ISSN 1112-9867

Available online at

http://www.jfas.info

\title{
DIAGNOSIS OF ROTOR FAULT USING NEURO-FUZZY INFERENCE SYSTEM
}

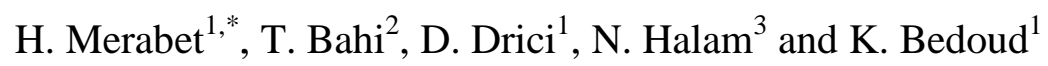 \\ ${ }^{1}$ Research Center in Industrial Technologies (CRTI) P.O. Box 64, Cheraga, Algeria. \\ ${ }^{2}$ Electrical Department, University of Annaba, Algeria \\ ${ }^{3}$ Faculty of Technology, University of El-oued, PO Box 789 El-oued 39000, Algeria
}

Received: 14 September 2016 / Accepted: 18 December 2016 / Published online: 01 January 2017

\begin{abstract}
The three-phase induction machines (IM) is large importance and are being widely used as electromechanical system device regarding for their robustness, reliability, and simple design with well developed technologies. This work presents a reliable method for diagnosis and detection of rotor broken bars faults in induction machine. The detection faults are based on monitoring of the current signal. Also the calculation of the value of relative energy for each level of signal decomposition using package wavelet, which will be useful as data input of adaptive Neuro-Fuzzy inference system (ANFIS).
\end{abstract}

In this method, fuzzy logic is used to make decisions about the machine state. The adaptive Neuro-Fuzzy inference system is able to identify the IM bearing state with high precision.

This technique is applied under the MATLAB ${ }^{\circledR}$.

Keywords: Induction Machine; Diagnosis; Detection; Neuro-Fuzzy inference system.

Author Correspondence, e-mail: h.merabet@crti.dz

doi: http://dx.doi.org/10.4314/jfas.v9i1.12

\section{INTRODUCTION}

The induction Machines (IM) are used in many fields, such as electrical drives system and main component of any industrial area that involve production processes [1,2]. In spite of their low cost, reliability and robustness, breakdown in electrical machines lead to failure of 
the entire production system which cause considerable financial losses. Consequently, early detection faults are very helpful for avoiding failure and allow minimizing the downtime [3]. Stator winding fault is one of the major faults of these machine types [4, 5].

The presence of a broken bar in the cage rotor produces a geometric and electromagnetic asymmetry in the rotor circuit, and induced currents are created in direct rotating field, another field is turning around [6].

According to the literature, there are many techniques of the detection of stator and rotor faults in electrical machines drives, especially, the methods based on time domain or frequency domain techniques, which have been proposed to detect stator failures. A more intensive research efforts have been focused on frequency signature analysis for stator and rotor faults using different signals such as; machine currents, the motor current signature analysis (MCSA) combined with wavelet, wavelet transform (WT) applied to different signals, current envelope (CE), extended Park's vector approach (EPVA), instantaneous power signature analysis (IPSA), Short-Time Fourier Transform (STFT), support victor machine (SVM), etc, $[7,8]$. The artificial intelligences based on fuzzy logic system inference, artificial neural network (ANN) or combined structure techniques of artificial neural fuzzy interference system (ANFIS) are widely used in the new monitoring techniques of induction machines [9, $10]$.

Therefore, in order to increase the efficiency and the reliability of the monitoring in the field of the (IM) supervision, the proposed technique is based on Neuro-Fuzzy inference system (ANFIS). In the aim to analyzing the faults, the global mathematical model of induction machine is developed and simulated via software MATLAB ${ }^{\circledR} /$ SIMULINK.

\section{INDUCTION MOTOR MODEL}

\section{1.Multi meshes model of rotor broken bars fault}

The mathematical model of squirrel cage induction motor can be written in vector matrix from as follows [11]:

$$
[V]=[R][I]+\frac{d}{d t}([L][I])
$$


Where;

The matrix of voltage and currant respectively as fllows by :

$$
\begin{gathered}
{[V]=\left[\begin{array}{l}
{\left[V_{S}\right]} \\
{\left[V_{R}\right]}
\end{array}\right]} \\
{[I]=\left[\begin{array}{l}
{\left[I_{S}\right]} \\
{\left[I_{R}\right]}
\end{array}\right]}
\end{gathered}
$$

With;

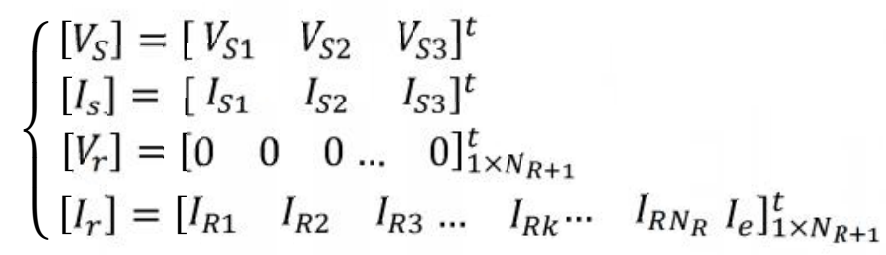

The global resistance matrix can be written as:

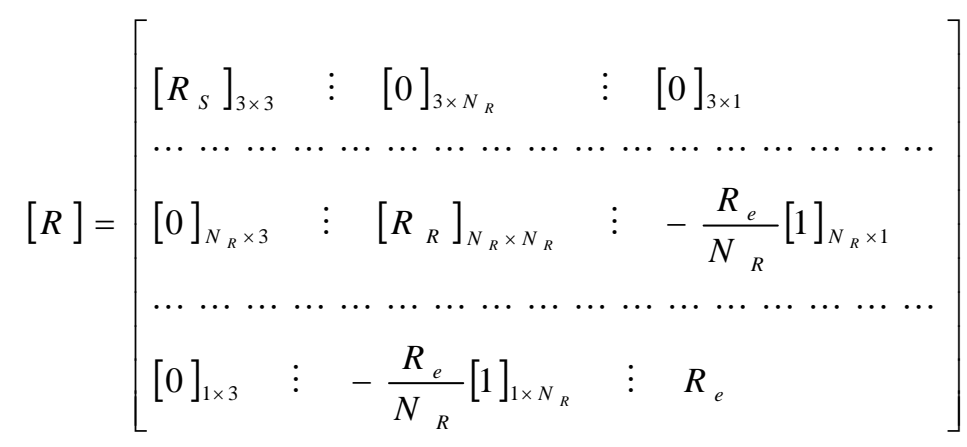

Where;

The matrix of stator resestance is given by:

$$
\left[R_{S}\right]_{3 \times 3}=\left[\begin{array}{ccc}
R_{S} & 0 & 0 \\
0 & R_{S} & 0 \\
0 & 0 & R_{S}
\end{array}\right]
$$

The matrix of stator resestance is given by: 


$$
\left[R_{R}\right]_{N_{R} \times N_{R}}=\left[\begin{array}{ccccccccc}
R_{b_{0}}+R_{b_{\left(N_{R}+1\right)}}+\frac{2 R_{e}}{N_{R}}-R_{b_{0}} & 0 & \cdots & \cdots & 0 & -R_{b_{\left(N_{R}+1\right)}} \\
0 & \cdots & -R_{b_{\left(N_{R}-1\right)}} & R_{b_{k}}+R_{b_{\left(N_{R}-1\right)}}+\frac{2 R_{e}}{N_{R}} & -R_{b k} & 0 & \cdots & 0 \\
-R_{b_{\left(N_{R}-1\right)}} & 0 & \cdots & 0 & -R_{b_{\left(N_{R}-2\right)}} & R_{b_{\left(N_{R}-1\right)}}+R_{b_{\left(N_{R}-1\right)}}+\frac{2 R_{e}}{N_{R}}
\end{array}\right]
$$

The mutual inductance matrix between stator phases and rotor mesh iis following by:

$$
\left[M_{S R}\right]_{N_{R} \times 1}=\left[\begin{array}{ccc}
\cdots & -M_{S R} \cos (\theta+k a) & \cdots \\
\cdots & -M_{S R} \cos \left(\theta+k a-\frac{2 \pi}{3}\right) & \cdots \\
\cdots & -M_{S R} \cos \left(\theta+k a-\frac{4 \pi}{3}\right) & \cdots
\end{array}\right]
$$

The matrix of inductances of stator phases expressed by the relationship (9) is of the order $(m, m)$ with $m=3$ :

$$
\begin{aligned}
& {\left[L_{S}\right]_{3 \times 3}=\left[\begin{array}{ccc}
L_{S p} & M_{S} & M_{S} \\
M_{S} & L_{S p} & M_{S} \\
M_{S} & M_{S} & L_{S p}
\end{array}\right]} \\
& {\left[L_{R p}+2 L_{b}+\frac{2 L_{e}}{N_{R}} \quad M_{R R}-L_{b} \quad M_{R R}\right.} \\
& M_{R R}-L_{b} L_{R p}+2 L_{b}+\frac{2 L_{e}}{N_{R}} M_{R R}-L_{b} \\
& {\left[L_{R}\right]=\quad \begin{array}{llllll}
M_{R R} & M_{R R}-L_{b} & L_{R p}+2 L_{b}+\frac{2 L_{e}}{N_{R}}
\end{array}} \\
& \begin{array}{lllllll}
M_{R R} & & \vdots & & & \ddots \\
\vdots & & & \ddots & & & \ddots \\
M_{R R} & -L_{b} & M_{R R} & M_{R R}
\end{array}
\end{aligned}
$$

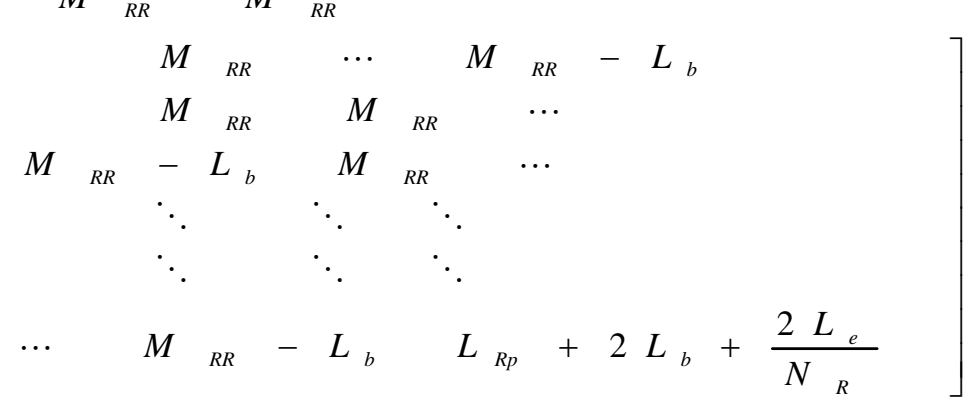

This is introduced in the matrix of resistances by the addition of the matrix of the rotor resistance $\left[R_{R}\right]$ with the default matrix $\left[R_{d}\right]$. 


$$
\left[R_{d}\right]=\left[\begin{array}{ccccc}
0 & 0 & 0 & \cdots & 0 \\
\vdots & 0 & \cdots & \cdots & 0 \\
\vdots & R_{k, k} & R_{k, k+1} & 0 & \vdots \\
0 & R_{k+1, k} & R_{k+1, k+1} & \vdots & \vdots \\
0 & \cdots & \cdots & 0 & 0
\end{array}\right]
$$

In case of the broken bar, the value of resistance this bar is multiplied by a factor of $M=10^{3}$.

With;

$$
\begin{aligned}
& R_{k, k}=R_{k+1, k+1}=(M+1) \times R_{b}+2 \times R_{e} \\
& R_{k+1, k}=R_{k, k+1}=(-M) \times R_{b}
\end{aligned}
$$

So, the squirrel cage resistance matrix, taking into account the defect, is defined by following:

$$
\left[R_{R d}\right]=\left[R_{R}\right]+\left[R_{d}\right]
$$

\section{RESULTS AND DISCUSSION WAVELET PACKET METHOD}

\subsection{The decomposition level}

The decomposition level of the approximation signal which includes the left side band harmonic is the integer $n_{L S}$ given by:

$$
n_{L S}=\operatorname{int}\left(\frac{\log \left(\frac{f_{S}}{f}\right)}{\log (2)}\right)
$$

For this approach, further decomposition of this signal has to be done so that the frequency band $[0-f]$ will bedecomposed in more bands. Usually, two additionaldecomposition levels (that is, $n_{L S}+2$ ) would be adequate for the analysis [12]:

$$
\begin{gathered}
n_{L S}+2=\operatorname{int}\left(\frac{\log \left(\frac{10000}{50}\right)}{\log (2)}\right)+2 \\
\operatorname{int}(7.64)+2=9 \text { levels }
\end{gathered}
$$

\subsection{Energy Level of the wavelet decomposition}

The multilevel decomposition of the stator current was then performed using Daubechies wavelet, the suitable level of decomposition is calculated according to Eq. (14). When the 
defect of the rotor bars, on the stator windings of the induction motor appear, the faults information in stator current is included in each frequency band determined by the decomposition in wavelet or in wavelet packet. By calculating the energy associated to each level or with the each node of decomposition, one can build a very effective diagnosis tool. The energy proper value for each frequency band is defined by $[13,15]$ :

$$
E_{j}=\sum_{k=1}^{k=n}\left|D_{j, k}(n)\right|^{2}
$$

Based on the energy eigen value, the eigenvector is set up as:

$$
T=\left[\frac{E_{0}}{E}, \frac{E_{1}}{E}, \frac{E_{2}}{E} \ldots \ldots \frac{E_{2} m_{-1}}{E}\right]
$$

Where $D_{j}$ is the amplitude in each discrete point of the wavelet coefficient of the signal in the corresponding frequency band with:

$$
E=\sum_{j=0}^{2^{m}-1}\left|E_{j}\right|^{2}
$$

The proper value $\mathrm{T}$ contains information on the signal of the stator current for a motor behavior. Besides, the amplitudes of the deviation of some proper values indicate the severity of the defect, which makes $\mathrm{T}$ a good candidate to diagnose broken bars of the rotor.

\section{ADAPTIVE NEURO-FUZZY INFERENCE SYSTEM}

ANFIS is a hybrid controller structure using fuzzy logic inference system and the architecture of a neural network having five-layer feed-forward structure [16, 17]. Thus, the ANFIS offers the advantages of learning capability of neural networks and inference mechanism of fuzzy logic. A typical architecture of ANFIS having $n$ inputs, one output, and $m$ rules is illustrated in Figure. 1 . 
Here $x, y, z$ and up to $\mathrm{n}$ are inputs, $f$ is output, the cylinders represent fixed node functions and the cubes represent adaptive node functions. This is a Sugeno type fuzzy system, where the fuzzy IF-THEN rules have the following form:

- Rule1: if $\mathrm{x}$ is $\mathrm{A}_{1}$ and $\mathrm{y}$ is $\mathrm{B}_{1}$ ..$n$ is $\mathrm{k}_{1}$ then $f_{l}=\left(p_{1} x+q_{1} y+r_{1} z+\ldots \ldots v_{1}\right)$

- Rule2: if $\mathrm{x}$ is $\mathrm{A}_{2}$ and $\mathrm{y}$ is $\mathrm{B}_{2}$ $\mathrm{n}$ is $\mathrm{k}_{2}$ then $f_{2}=\left(p_{2} x+q_{2} y+r_{2} z+\ldots \ldots v_{2}\right)$.

- $\quad \vdots \quad \vdots \quad \vdots \quad \vdots$

- $\quad \vdots \quad \vdots \quad \vdots \quad \vdots$

- Rule $\mathrm{m}$ : if $\mathrm{x}$ is $\mathrm{A}_{\mathrm{m}}$ and $\mathrm{y}$ is $\mathrm{B}_{\mathrm{m}}$ ..$n$ is $k_{m}$ then $f_{2}=\left(p_{m} x+q_{m} y+r_{m} z+\ldots \ldots v_{m}\right)$.

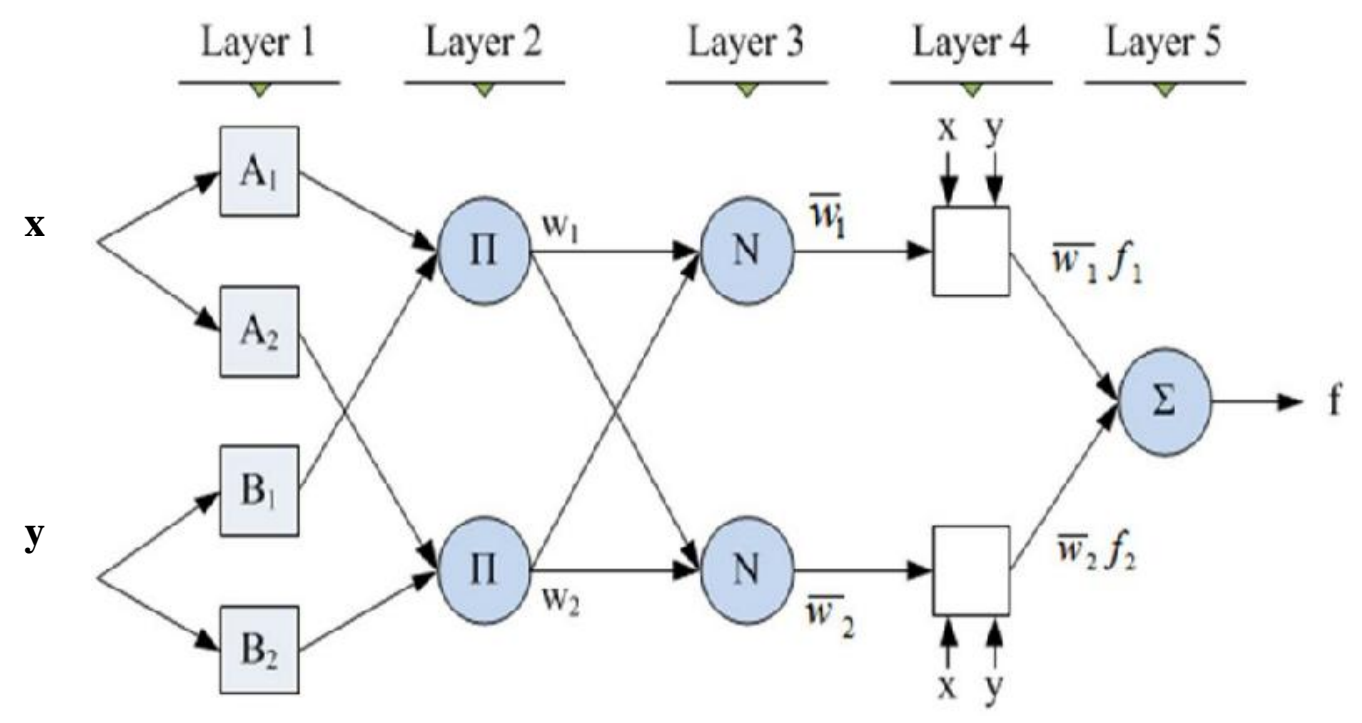

Fig.1. Typical ANFIS structure

In this paper we are using the current signals as the input nodes, and the output is the estimated machine state. The mechanical and electrical fault conditions are classified (Broken bars,. The ANFIS model provides the output value which can be used for advance decision making, also to go for preventive maintenance or to program of the maintenance. 
The suggested model for monitoring system is developed under Matlab/Simulink. Data base is collected from off-line is used the energy associated to each level or with the each node of decomposition of stator current signal. The inputs are translated into three different Gaussian membership functions and 64 rule base.

\section{RESULTS AND DISCUSSION}

The Figure 2 and Figure 3 illustrate, respectively, the stator current phase " $I_{s a}$ " in healthy case and the stator current phase " $I_{s a}$ " in broken rotor bar with Zoom presented to show the envelopes appear on the ends of the current .

Figure 4 present the variation of decomposition energy level of wavelet in the 16 frequency bands for healthy function case and in the presence of fault broken rotor bars in the induction machine.

The ANFIS model generates eight input membership functions of Gaussian structure and is run for 500 Epochs. The error for the training and checking output are found to be $0.004 \%$ shown in Figure.5.

The trained and checked ANFIS output for different types of fault diagnosis are shown in Figure. 6.

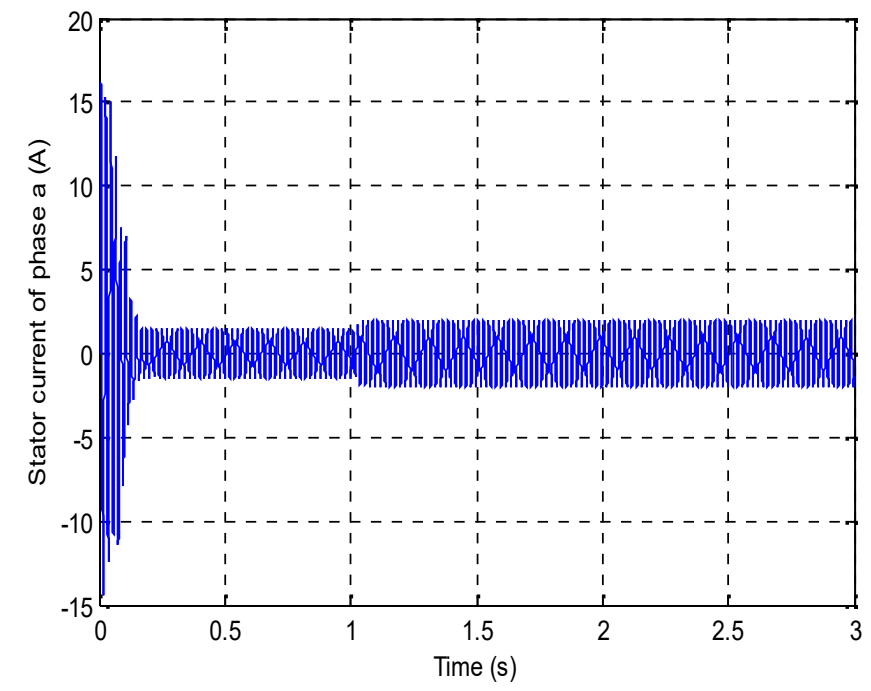

Fig.2. Stator current in healthy case

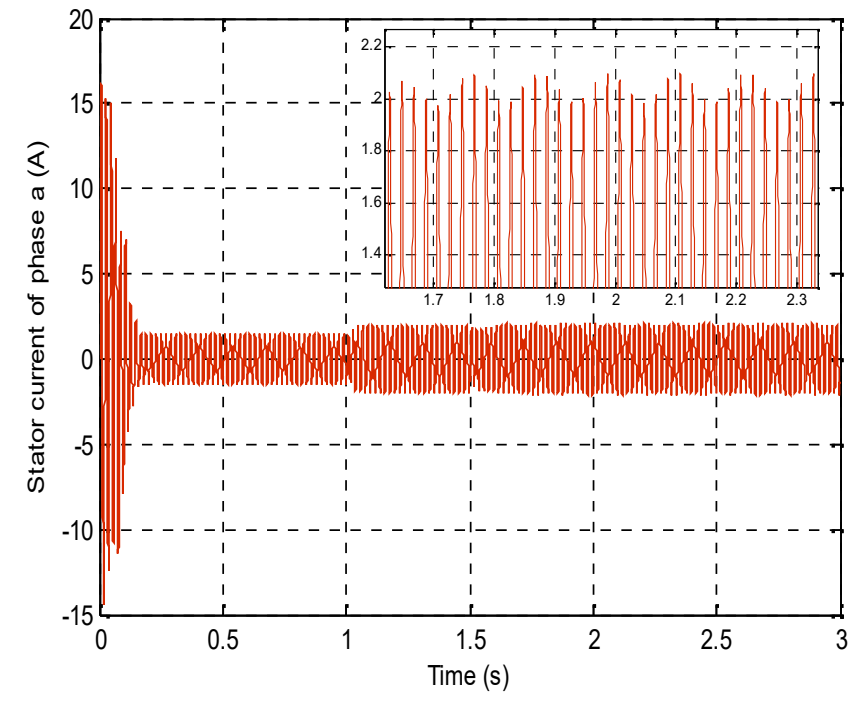

Fig.3. Stator current in broken rotor faults case

The input relationships or dependency for the ANFIS output are in addition analyzed. These 
are the unique characteristics of adaptive neuro-fuzzy inference system. The mapping is optimized by neuro adaptive learning techniques by fuzzy modeling procedure to learn information about the data set for monitoring the stat of induction machine in our case study.

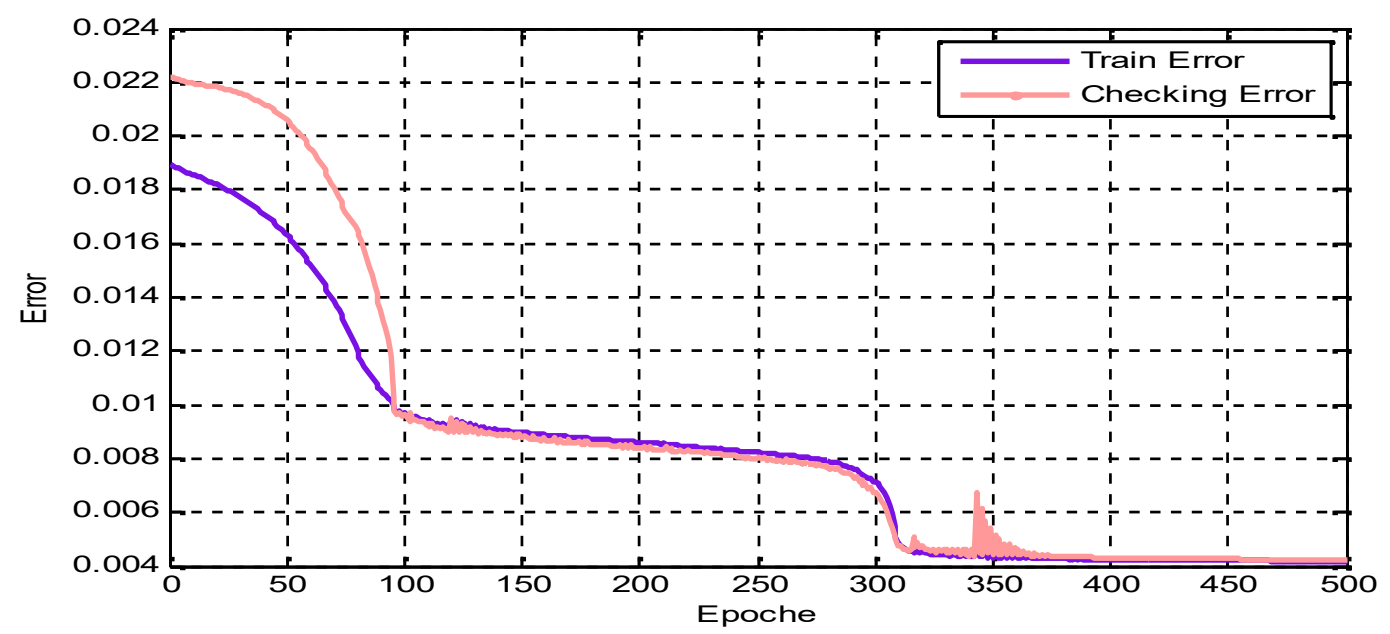

Fig. 5. Error curve of the ANFIS controller (Rotor broken rotor bars)

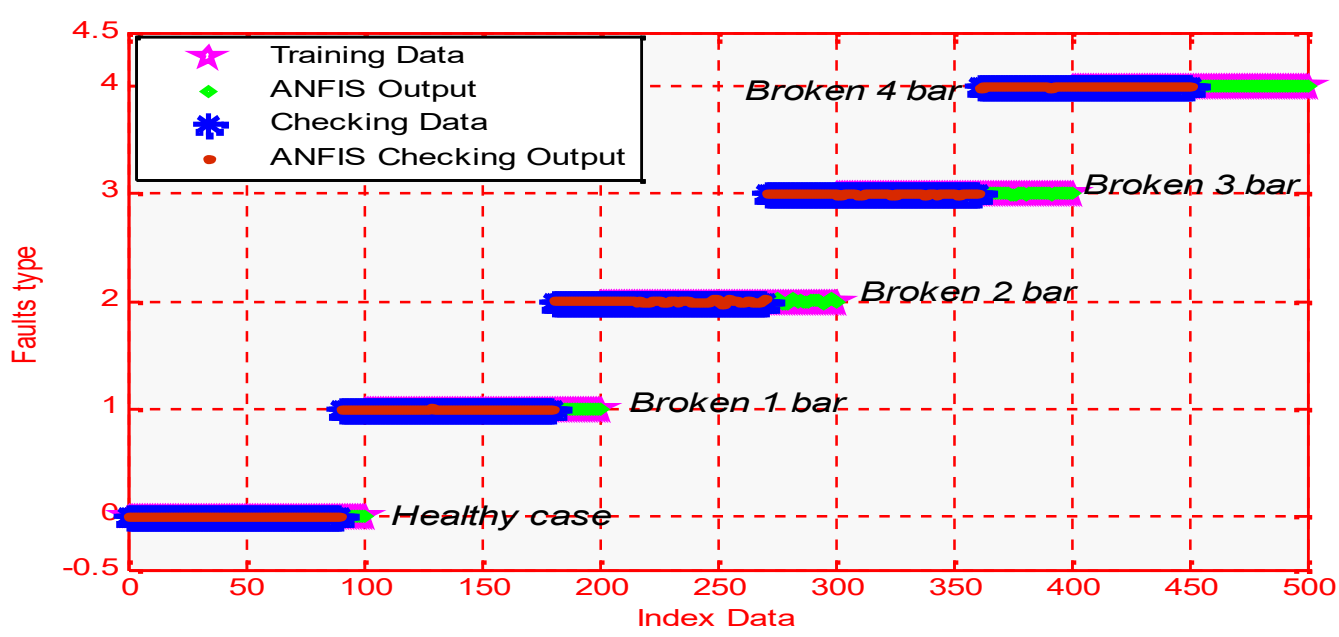

Fig.6. Training, Testing and Checking Output for the ANFIS controller (Rotor broken rotor bars)

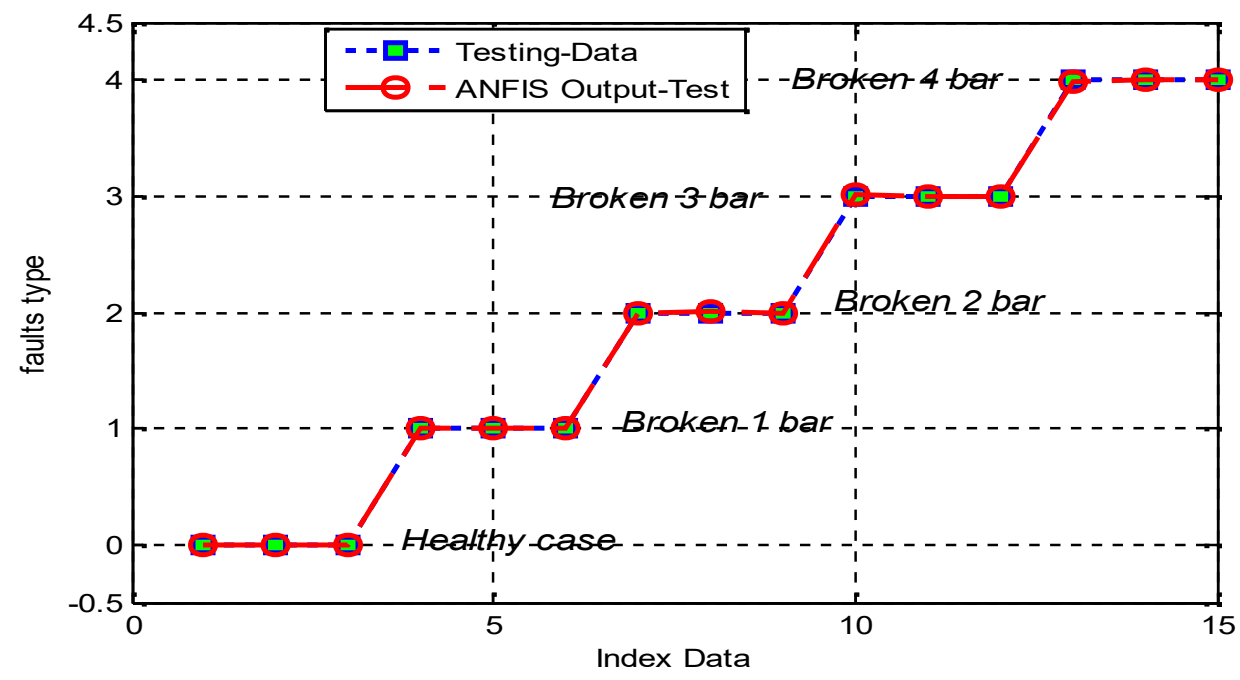

Fig.7. Testing Data and Testing Output for the ANFIS controller (Rotor broken rotor bars) 
To validate our network (shown the Fig.7), a test of recognition is carried out. The results are consigned in the following table (Show Tab.1).

Table 1. Numerical values of input-output for validate ANFIS

\begin{tabular}{|c|c|c|c|c|}
\hline \multicolumn{2}{|c|}{ Input } & \multirow{2}{*}{$\begin{array}{l}\text { Desired } \\
\text { Output }\end{array}$} & \multirow{2}{*}{$\begin{array}{c}\text { Estimated } \\
\text { Output }\end{array}$} & \multirow{2}{*}{$\begin{array}{l}\text { Observations } \\
\text { of the Error }\end{array}$} \\
\hline$x$ & $y$ & & & \\
\hline \multicolumn{5}{|c|}{ HEALTHY CASE } \\
\hline 95.5056 & 366.6240 & 0.0000 & 0.0000 & 0.0000 \\
\hline 96.5848 & 380.2702 & 0.0000 & -0.0000 & 0.0000 \\
\hline 98.1150 & 405.8460 & 0.0000 & 0.0000 & 0.0000 \\
\hline \multicolumn{5}{|c|}{1 BROKEN BARS } \\
\hline 61.6177 & 351.4025 & 1.0000 & 1.0011 & -0.0011 \\
\hline 61.6177 & 366.5898 & 1.0000 & 0.9993 & 0.0007 \\
\hline 65.3050 & 412.7210 & 1.0000 & 0.9987 & 0.0013 \\
\hline \multicolumn{5}{|c|}{2 BROKEN BARS } \\
\hline 56.7994 & 381.6860 & 2.0000 & 1.9998 & 0.0002 \\
\hline 58.1560 & 398.6990 & 2.0000 & 2.0022 & -0.0022 \\
\hline 59.3361 & 416.9158 & 2.0000 & 1.9877 & 0.0023 \\
\hline \multicolumn{5}{|c|}{3 BROKEN BARS } \\
\hline 57.3547 & 434.1678 & 3.0000 & 3.0076 & -0.0024 \\
\hline 60.0000 & 480.0000 & 3.0000 & 2.9938 & 0.0062 \\
\hline 62.5511 & 520.7533 & 3.0000 & 3.0009 & -0.0001 \\
\hline \multicolumn{5}{|c|}{4 BROKEN BARS } \\
\hline 53.0000 & 462.0000 & 4.0000 & 3.9895 & 0.0205 \\
\hline 55.8730 & 500.4854 & 4.0000 & 4.0011 & -00.11 \\
\hline 59.0201 & 550.6706 & 4.0000 & 3.9993 & 0.0007 \\
\hline
\end{tabular}




\section{CONCLUSION}

In this paper, we presented the development of a fault model of the induction machine then the simulation of this type faults. We initially presented in the first part the mathematical model of rotor broken bars faults.

In the second part of this work, the ANFIS approach is used to diagnose rotor broken bars faults in the induction machine, the adaptive neuro-fuzzy system inference indicator is based on the analysis of magnitude of energy level of the wavelet decomposition for stator current, in addition used for off-line training and checking of ANFIS in deferent fault types.

\section{REFERENCES}

[1] J. Seshadrinath, B. Singh, and B. Ketan Panigrah, "Investigation of Vibration Signatures for Multiple Fault Diagnosis in Variable Frequency Drives Using Complex Wavelets", IEEE Transaction on power electronics, vol. 29, no. 2, pp 936-945. Feb 2014.

[2] C. da Casta, M. Kashiniwagi, M. Hugo. Marthias, "Rotor failure detection of induction motors by wavelet transform and fourier transform in non-stationary condiction ", Case studies in Mechanical Systems and signal processing, Vol 1, pp 15-26, 2015.

[3] F. Babaa, A. Khezzar, M.El Kamel Oumaamar, "Experimental investitgation and comparative study of inerturn short-circuits and unbalanced voltage supply in induction machines", Front. Energy, Vol .7 issue 3, pp 271-278. 2013.

[4] S.M. Shashidhara and P.S. Raju, "Stator Winding Fault Diagnosis of Three Phase Induction Motor by Park's Vector Approach”, Internatonal Journal of Advance Research In Electircal Electronics and Instrumentation Engineering, Vol.2, pp. 2901-2906, Issue, 7, July. 2013.

[5] S.S. Moosavi, A. Djerdir, Y. Ait-Amirat, D. A. Khaburi,, “ ANN based fault diagnosis of permanant magnrt synchronous motor under stator winding shorted turn”, Electrical power system Research Vol 125, pp 67-82, 2015.

[6] A. Singh, B. Grant, R. DeFour, C. Sharma, S. Bahadoorsingh, "A review of induction motor fault modeling," Electric Power Systems Research, Vol 133, pp 191-197, 2016. 
[7] Houssin El Bouchikhi, Vincent Choqueuse, Mohamed Benbouzid, "Induction machine faults detection using stator current parametric spectral estimation," Mechanical Systems and Signal Processing, Vol 52-53, pp 447-464, 2015.

[8] X. zhang, Y. liahg, J.Zhou , “ a novel bearing fault diagnosis model integrated permutation entropy, ensemble empirical mode decomposition and optimized SVM", Measurement, Vol 69,pp164-179.2015.

[9] H. Eristi, "Fault diagnosis system for series compensated transmission line based on wavelet transform and adaptive neuro-fuzzy inference system”, Measurement, Vol 46, pp 393-401. 2013.

[10] P. Subbaraj, B. Kannapiran , “Fault detection and diagnosis of pneumatic valve using Adaptive Neuro-Fuzzy Inference System approach”,Applied Soft Computing, Vol 19, pp, 362-371, 2014.

[11] Pu. Shi, zheng chen, Y. Vagapov, Z. Zouaoui , "A new diagnosis of broken rotor bar fault extent in three phase squirrel cage induction motor", Mechanical System and Signal Processing, Vol 42, pp 388-403, 2014.

[12] N Lashkari, J Poshtan, HF Azgomi,“ Simulative and experimental investigation on stator winding turn and unbalanced supply voltage fault diagnosis in induction motors using Artificial Neural Networks”, ISA Transactions, Vol 59, pp 334-342, 2015.

[13] K. Moin Siddiqui, K. Sahay, V.K.Giri, "Health Monitoring and Fault Diagnosis in Induction Motor", International Journal of Advanced Research in Electrical, Electronics and Instrumentation Engineering Vol. 3, January 2014.

[14] K. Moin Siddiqui and V.K.Giri,“ Broken Rotor Bar Fault Detection in Induction Motors using Wavelet Transform", Int. Conf Proc, IEEE, Computing, Electronics and Electrical Technologies [ICCEET], pp. 1-6, Chennai, India, March, 2012.

[15] A. Bouzida, O. Touhami, Abddelli ,“ application de la technique des ondelettes au diagnostic de défauts de la machine asynchrone a rotor à cage”, RerN VOL 15, N4 ? PP 549-557, 2014.

[16] Haitham Abu-Rub, S. M.Ahmed, Shady S. Refaat, Atif Iqbal, “incipient bearing fault detection for three phase bruchless DC Motor Drive usin ANFIS”, IEEE, 2011. 
[17] S. M.Ahmed, Haitham Abu-Rub, Shady S. Refaat, Atif Iqbal, "Diagnosis of Stator Turn-to-Turn Fault and Stator Voltage Unbalance Fault Using ANFIS", International Journal of Electrical and Computer Engineering (IJECE) Vol.3, No.1, , pp. 129 135 ISSN: 2088-8708, February 2012.

\section{How to cite this article:}

Merabet H, Bahi T, Drici D, Halam N, Bedoud K. Diagnosis of rotor fault using neuro-fuzzy inference system. J. Fundam. Appl. Sci., 2017, 9(1), 170-182. 